\title{
PERAN JOB CRAFTING SEBAGAI MEDIASI LEARNING GOAL ORIENTATION DAN WORK ENGAGEMENT
}

\author{
Terry Luana Ameliasari \\ Universitas Negeri Surabaya \\ terrya.16080574009@mhs.unesa.ac.id
}

\begin{abstract}
This study aims to determine the role of job crafting as a mediation between learning goal orientation towards work engagement. This research is a quantitative study using a questionnaire method. The sample in this study was 51 employees of PT. Boma Bisma Indra (Persero) Surabaya. Data analysis used Structural Equation Model with the help of the SmartPLS 3.0 program. The results in this study indicate: (1) there is a significant positive effect of learning goal orientation on work engagement, with the t-statistics value of 3,432; (2) there is a significant positive effect of learning goal orientation on job crafting, with the t-statistics value of 8,234; (3) there is a significant positive effect of job crafting on work engagement with the $t$-statistic value of 4,931; (4) job crafting mediates the effect of learning goal orientation on work engagement, with the t-statistics value of 3,987 then the hypothesis was accepted.
\end{abstract}

Keywords: job crafting; learning goal orientation; work engagement.

\section{PENDAHULUAN}

Hal yang lazim bahwa perusahaan memiliki tujuan untuk dicapai. Guna mencapai tujuan tersebut terdapat beberapa hal yang diperlukan, salah satunya yaitu Sumber Daya Manusia (SDM). Bahkan di dalam struktur perusahaan terdapat departemen sumber daya manusia. Departemen bertugas mengelola seluruh karyawan yang ada pada perusahaan. Perusahaan dengan potensi (aset) yang unggul jika tidak disertai dengan sumber daya manusia yang unggul pula maka menjadi sia-sia (Sasmita, 2018).

Dalam sebuah perusahaan, departemen sumber daya manusia berperan dalam mengelola karyawan diantaranya dengan meningkatkan kemampuan dan pengetahuan, mengembangkan keterampilan dan bakat, hal tersebut bertujuan agar kinerja karyawan dapat meningkat. Ketika sumber daya manusia dikelola dengan baik, maka harapannya kontribusi karyawan dalam capaian misi perusahaan dapat lebih optimal (Bukit et al., 2017).

Sumber daya manusia yang unggul dapat dihasilkan ketika perusahaan dapat mengelola dengan baik, salah satu cara yang sering digunakan yaitu mengarahkan karyawan untuk terikat dalam pekerjaan. Keterikatan kerja yang dimiliki karyawan dengan perusahaan membuat mereka memberikan kontribusinya terhadap perusahaan untuk memajukan perusahaan, dan hal itu akan menjadi kebanggaan tersendiri bagi karyawan tersebut. Dengan adanya keterikatan kerja dari karyawan serta kontribusi aktif pada perusahaan, merupakan pertanda bahwa iklim kerja yang positif dimiliki oleh perusahaan tersebut (Turpunjung, 2017). Karyawan yang memiliki keterikatan yang baik, mempunyai antusias yang cenderung tinggi dalam bekerja. Tidak hanya itu, tugas utama mereka yang tertera pada kontrak kerja terkadang dapat dilampaui lebih jauh (Yuswardi, 2019).

Work engagement didefinisikan sebagai kepuasaan yang dirasakan oleh karyawan juga rasa bahagia yang ditandai dengan adanya antusias, dedikasi serta penghayatan terhadap pekerjaannya (Schaufeli \& Bakker, 2004). Karyawan yang mempunyai keterikatan kerja terhadap perusahaan cenderung mempunyai kondisi jiwa yang puas dan bahagia dalam melakukan pekerjaannya, sehingga secara intrinsik karyawan akan memiliki keinginan untuk belajar, menambah pengetahuan baru dan mengembangkannya sebagai bentuk kontribusinya terhadap perusahaan (Demerouti et al., 2015). Menurut Dweck (1986), learning goal orientation (LGO) adalah sifat disposisi stabil individu yang menunjukkan keinginan untuk belajar dan menguasai keterampilan dan situasi baru. Learning goal orientation juga didefinisikan sebagai pola pikir internal yang mendorong karyawan untuk menambah pengetahuan mereka dengan mempelajari bakat baru. Penelitian sebelumnya telah menunjukkan bahwa 
individu yang menerapkan learning goal orientation memandang pekerjaan yang menantang sebagai sebuah kesempatan untuk belajar (Dragoni et al., 2009). Pendapat tersebut didukung oleh penelitian dari Jones et al., (2015) di mana terdapat pengaruh positif antara learning goal orientation dan work engagement.

Learning goal orientation tidak hanya memengaruhi work engagement, namun juga memengaruhi job crafting (Matsuo, 2018). Menurut Wrzesniewski \& Dutton (2001) job crafting merupakan proses pembentukan pekerjaan dengan mengubah kognitif, tugas, dan batasan relasional sehingga terbentuk interaksi antar satu sama lain dalam lingkup dunia kerja. Learning goal orientation secara intrinsik dapat memotivasi karyawan untuk dapat merancang pekerQA jaan mereka sehingga menjadi pekerjaan yang lebih menantang, yang kemudian akan lebih memberikan pembelajaran dan keterikatan melakukan pekerjaan mereka (Vansteenkiste et al., 2006). Argumen tersebut didukung oleh penelitian dari Lu et al., (2014), dan Petrou et al., (2012) yang dalam penelitiannya menjelaskan bahwa learning goal orientation dapat berpengaruh terhadap job crafting.

Tujuan penelitian ini adalah untuk mengetahui pengaruh learning goal orientation terhadap work engagement melalui job crafting.

\section{KAJIAN PUSTAKA DAN PENGEMBANGAN HIPOTESIS}

\section{Work Engagement}

Work engagement diartikan sebagai keadaan atau kondisi karyawan yang merasakan adanya kepuasan dan perasaan bahagia yang ditandai dengan antusias, pengabdian serta pendalaman terhadap pekerjannya (Schaufeli \& Bakker, 2004). Radstaak \& Hennes (2008) mengartikan work engagement merupakan segala kondisi dalam pekerjaan yang berkaitan dengan tekad yang positif sehingga menghasilkan sesuatu yang afektif dan memuaskan dalam suatu pekerjaan. Work engagement juga diartikan sebagai bentuk motivasi intrinsik, di mana perilaku tersebut dilakukan untuk dirinya sendiri untuk mendapatkan kesenangan dan memiliki semangat dalam melakukan pekerjaannya (Demerouti et al., 2015). Kahn (1990) menjelaskan bahwa seseorang yang menerapkan work engagement akan mengidentifikasi dirinya dengan pekerjaan, di mana orang tersebut akan mempekerjakan dan mengekspresikan dirinya secara kognitif, fisik, dan emosional selama bekerja. Seseorang yang terikat dalam pekerjaannya akan berkomitmen terhadap tujuan, menggunakan segenap kemampuan untuk menyelesaikan tugas, menjaga perilakunya saat bekerja, memastikan bahwa telah menyelesaikan tugas dengan baik sesuai dengan tujuan dan bersedia memperbaiki dan mengevaluasi pekerjaannya jika memang diperlukan (Marciano, 2010).

\section{Learning Goal Orientation}

Learning goal orientation adalah sifat disposisi stabil seseorang yang menunjukkan keinginan untuk belajar dan menguasai keterampilan dan situasi baru (Dweck, 1986). Learning goal orientation juga didefinisikan sebagai pola pikir internal yang mendorong karyawan untuk menambah pengetahuan mereka dengan mempelajari bakat baru. Learning goal orientation seringkali diiringi dengan kegigihan seseorang ketika dihadapkan pada suatu permasalahan dan memiliki keinginan untuk mencari alternatif penyelesaian masalah, serta menikmati masalah yang sedang dihadapi (Eppler \& Harju, 1997). VandeWalle (1997) menyatakan bahwa learning goal orientation merupakan suatu kemauan dari setiap individu dalam mengembangkan kompetensi dirinya dengan cara mempelajari keterampilan baru dan menghadapi sebuah kondisi yang belum pernah dihadapi sebelumnya. Menurut Joo \& Park (2010) learning goal orientation merupakan kemauan seseorang untuk meningkatkan kompetensi dengan mengembangkan keterampilan dan menguasai situasi baru, ditandai dengan adanya pola respons adaptif sehingga mengarahkan kepada hasil yang positif. Seseorang yang memiliki learning goal orientation memandang inteligensi sebagai suatu hal yang fleksibel dan dapat dikembangkan secara terus menerus melalui pengalaman dan usaha (Creed et al., 2009).

\section{Job Crafting}

Job crafting merupakan proses perancangan pekerjaan dengan mengubah kognitif, tugas, dan batasan relasional untuk berinteraksi dengan rekan kerja (Wrzesniewski \& Dutton, 2001). Sedangkan 
Demerouti (2014) menjelaskan bahwa job crafting merupakan perilaku proaktif dan inisiatif dari karyawan untuk mengubah beban kerja mereka agar lebih berguna, memuaskan dan juga menarik. Menurut Tims et al. (2015), job crafting juga mengartikan sebagai perilaku proaktif dari karyawan, di mana hal ini menunjukkan bahwa karyawan memiliki niat untuk merancang suatu pekerjaan dan merealisasikan niat tersebut. Terlebih lagi, perilaku proaktif menunjukkan insiatif untuk melakukan perubahan, mengantisipasi dan mengendalikan lingkungan kerja seseorang. Menurut Slemp \& VellaBrodrick (2014), job crafting adalah suatu peran aktif yang dimiliki oleh karyawan untuk melakukan perubahan baik secara fisik dan kognitif dalam pekerjaannya yang bertujuan untuk memenuhi kebutuhan dan keinginan. Job crafting juga diartikan sebagai langkah individu dalam mengubah aspek dan persepsi untuk menyesuaikan kebutuhan dan karakteristik dari individu tersebut (Kirkendall, 2013). Menurut Setyawati \& Nugrohoseno (2019), job crafting secara independen memodifikasi aspek pekerjaan karyawan untuk meningkatkan kesesuaian antara karateristik pekerjaan dan kebutuhan, kemampuan, dan preferensi karyawan.

\section{Hubungan antar Variabel}

Matsuo (2018) dalam penelitiannya menyebutkan bahwa learning goal orientation berpengaruh positif terhadap work engagement, ditunjukkan bahwa individu yang memiliki learning goal orientation yang kuat akan menjadikan hal tersebut sebagai strategi yang berguna untuk meningkatkan kerajinan kerja dan keterlibatan kerja. Penyataan ini sejalan dengan studi oleh Maden (2015) dan Jones et al., (2015), di mana learning goal orientation terdapat pengaruh signifikan dengan arah positif terhadap work engagement. Penelitian dari Adriaenssens et al., (2015) juga menjelaskan bahwa mastery approach goal orientation berpengaruh kuat dalam peningkatan work engagement. Di mana dapat diartikan bahwa semakin tinggi learning goal orientation akan berpengaruh terhadap work engagement. Selain itu, Baum et al., (2011) dalam penelitiannya menyebutkan bahwa individu dengan learning goal orientation yang kuat lebih rentan untuk terlibat aktif dalam bereksperimen, di mana kemungkinan mereka akan lebih banyak untuk mengeksplorasi dan mempelajari pengetahuan baru melalui pengalaman pribadi dalam kehidupan nyata dan mencoba menerapkannya ke dalam pekerjaannya. Temuan ini menegaskan bahwa work engagement memiliki hubungan langsung terhadap learning goal orientation.

\section{H1: Diduga learning goal orientation berdampak positif bagi work engagement.}

Hasil penelitian dari Nabi \& Ismail (2016) menjabarkan bahwa learning goal orientation berhubungan positif terhadap job crafting. Dijelaskan dalam penelitiannya bahwa seseorang yang menerapkan learning goal orientation secara proaktif akan mendesain pekerjaan mereka dengan baik, di mana hal tersebut merupakan penerapan dari job crafting. Dari hal tersebut dapat diartikan bahwa semakin tingginya learning goal orientation pada karyawan akan berpengaruh terhadap job crafting karyawan. Hasil studi yang dilakukan oleh Yao \& Fu (2019) menjelaskan bahwa dalam lingkungan kerja, karyawan memerlukan adaptasi serta sikap "can $d o$ " untuk mencoba dan tumbuh, karyawan juga harus yakin dengan kemampuannya dengan diikuti oleh usaha. Dengan begitu, karyawan dengan pendekatan learning goal orientation berkesempatan untuk tumbuh dan memenuhi tujuan mereka, hal tersebut membuat mereka secara proaktif menerapkan job crafting. Penelitian dari Zhou (2003) menjelaskan bahwa karyawan yang menerapkan learning goal orientation akan memilik motivasi intrinsik serta menyukai pekerjaan yang menantang dan kompleks guna meningkatkan diri dalam pekerjaannya. Bahkan jika mereka kesulitan dalam menghadapi permasalahan, mereka tidak akan menyerah dan bahkan mereka akan berusaha lebih keras lagi untuk dapat menghadapi permasalahan tersebut. Hasil penelitian tersebut sejalan dengan penelitian yang dilakukan oleh Lyons et al., (2006) yang menemukan adanya perilaku learning goal orientation pada karyawan sektor publik dalam melakukan mendesain pekerjaannya, di mana mereka secara proaktif melakukan pekerjaan yang menantang. Penelitian dari Belschak \& Den Hartog (2010) menyebutkan bahwa karakteristik dari karyawan yang memiliki motivasi intrinsik dalam bekerja akan mencari tahu dan berkenan untuk mengambil tugas yang menantang.

\section{H2: Diduga learning goal orientation berdampak positif bagi job crafting}


Hasil penelitian Radstaak \& Hennes (2017) menjelaskan bahwa job crafting berdampak positif dengan work engagement. Penelitian tersebut menjelaskan jika karyawan yang memiliki energi positif dan memiliki antusias dalam bekerja akan secara aktif mengatur beban pekerjaannya menjadi lebih baik. Dalam penelitian Thomassen (2016) menjelaskan bahwa karyawan yang memiliki kemampuan untuk merancang pekerjaannya akan memiliki tingkat keterlibatan kerja yang tinggi. Sejalan dengan studi yang dilakukan oleh Bakker et al., (2016), lingkungan kerja yang menerapkan kerajinan kerja secara tifak langsung akan memengaruhi keterlibatan kerja satu dengan yang lain. Penelitian dari Lu et al., (2014) menyebutkan bahwasanya job crafting berdampak positif bagi work engagement, hal tersebut didukung penelitian dari Petrou et al., (2012) yang menyebutkan bahwa karyawan yang setiap harinya mencari tantangan dalam menyelesaikan pekerjaannya akan semakin terikat dengan pekerjaan. Dapat diartikan bahwa, job crafting akan memiliki dampak positif bagi work engagement karyawan.

H3: Diduga job crafting berdampak positif bagi work engagement

Job Crafting (seeking challenges) diketahui memiliki peran mediasi terhadap learning goal orientation dan work engagement. Hipotesis tersebut dapat dikatakan masuk akal karena job crafting (seeking challenges) dapat memediasi hubungan antara learning goal orientation dan work engagement, karena learning goal orientation mungkin secara instrinsik dapat memotivasi karyawan untuk mendesain ulang pekerjaan mereka menjadi lebih menantang, yang kemudian akan lebih meningkatkan keterikatan kerja karyawan. Hubungan tersebut dapat diprediksi melalui self-determination theory (SDT), yang mengusulkan untuk menggabungkan tujuan dan orientasi otonom untuk meningkatkan suatu keterikatan dan minat belajar individu di tempat kerja (Deci \& Ryan, 2008). Hasil penelitian dari Matsuo (2018) menunjukkan bahwa individu dengan perilaku learning goal orientation yang tinggi tidak hanya termotivasi secara intrinsik dalam memperoleh pengetahuan dan keterampilan tetapi juga mendesain ulang pekerjaan mereka menjadi lebih menantang. Dengan begitu dapat diartikan bahwa job crafting (seeking challenges) dapat menjadi mediasi pengaruh antara learning goal orientation terhadap work engagement. Hubungan antar variabel juga digambarkan di Gambar 1.

H4: Diduga learning goal orientation berpengaruh positif terhadap work engagement melalui job crafting

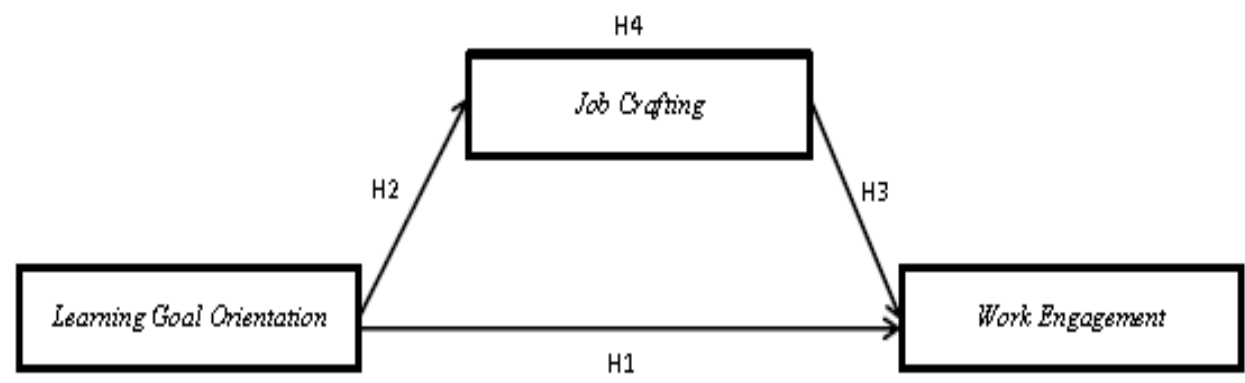

Gambar 1. KERANGKA KONSEPTUAL

\section{METODE PENELITIAN}

Studi ini adalah kuantitatif dengan jenis studi kausalitas. Penentuan sampel dipilih menggunakan purposive sampling, melalui pemilihan kriteria yaitu hanya menggunakan karyawan tetap PT. Boma Bisma Indra (Persero) Surabaya. Jumlah sampel yang dituju sebesar 79 orang, namun yang kembali hanya sebesar 51 orang. Media yang digunakan untuk menyebar kuesioner adalah Google Form. Structural equation modelling (SEM) merupakan analisis statistik pada studi ini, dengan memanfaatkan aplikasi SmartPLS versi 3.0. 


\section{HASIL DAN PEMBAHASAN}

\section{Uji Validitas}

Setiap indikator kuesioner sudah memenuhi nilai validitas yang baik, di mana hal tersebut didapat dari nilai outer loadings yang lebih besar dari 0,50. Model konstruk bisa disebut valid jika seluruh indikator memenuhi convergent validity.

\section{Composite Reliability}

Dalam pengujian suatu nilai dalam reliabilitas antara blok indikator dengan konstruk dalam variabel adalah menggunakan composite reliability. Reliabilitas dibilang baik jika nilai di atas 0,70 .

\section{Cronbach's Alpha}

Hasil Cronbach's alpha dapat meningkatkan composite reliability, disaat suatu variabel dibilang terbukti saat menghasilkan nilai di atas 0,60.

\section{R-Square}

$R$-Square dipakai guna menentukan berapa besarnya inner model yang dibentuk. Tabel 1 menjelaskan banyak nilai $R$-Square yang dipergunakan dalam penelitian ini. Model pengaruh learning goal orientation bagi work engagement menghasilkan koefisien $R$-Square sebanyak 0,754 , dan memiliki intepretasi variabel konstruk work engagement dapat diuraikan oleh variabel learning goal orientation sebesar 75,4\%. Kemudian sebesar 24,6\% diuraikan oleh variabel lain di luar studi ini. Nilai koefisien $R$-Square dari pengaruh learning goal orientation terhadap job crafting sebesar $45,1 \%$, sedangkan untuk 54,9\% tidak dideskripsikan oleh variabel dalam studi ini.

Tabel 1.

$R-S Q U A R E$

\begin{tabular}{lc}
\hline \multicolumn{1}{c}{ Variabel } & R-Square \\
\hline Learning Goal Orientation & \\
Work Engagement & 0,754 \\
Job Crafting & 0,451 \\
\hline Sumber: Output SmartPLS 3.0 (2020)
\end{tabular}

Tabel 1 menjelaskan banyak nilai $R$-Square yang dipergunakan dalam penelitian ini. Model pengaruh learning goal orientation bagi work engagement menghasilkan koefisien $R$-Square sebanyak 0,754 , dan memiliki intepretasi variabel konstruk work engagement dapat diuraikan oleh variabel learning goal orientation sebesar $75,4 \%$. Kemudian sebesar $24,6 \%$ diuraikan oleh variabel lain di luar studi ini. Nilai koefisien $R$-Square dari pengaruh learning goal orientation terhadap job crafting sebesar $45,1 \%$, sedangkan untuk 54,9\% tidak dideskripsikan oleh variabel dalam studi ini.

\section{Uji Kasualitas}

Inner model dipakai untuk melihat relasi dari variabel pada path coefficients dan hasil indirect effects. Tabel 2 menunjukkan bahwa hipotesis 1, hipotesis 2, dan hipotesis 3 diterima. Hal ini dikarenakan nilai yang dihasilkan lebih dari 1,96. Dari tabel 3 diketahui bahwa hipotesis 4 diterima, karena nilai $t$ statistics yang dihasilkan lebih dari 1,96. Di mana job crafting mampu memediasi pengaruh learning goal orientation terhadap work engagement.

\section{Pengaruh Learning Goal Orientation terhadap Work Engagement Karyawan PT. Boma Bisma Indra (Persero) Surabaya}

Nilai koefisien pengaruh learning goal orientation terhadap work engagement memiliki arah positif, yang mengindikasi bahwa learning goal orientation yang semakin tinggi akan meningkatkan work engagement. 
Terry Luana Ameliasari. Peran Job Crafting sebagai Mediasi Learning Goal Orientation dan Work Engagement

Tabel 2.

PATH COEFFICIENTS

\begin{tabular}{cccc}
\hline Hubungan antar Variabel & Origin Sample & T-Statistics & Keterangan \\
\hline Learning Goal Orientation $\rightarrow$ Work Engagement & 0,384 & 3,432 & $\geq 1,96$ (Signifikan) \\
Learning Goal Orientation $\rightarrow$ Job Crafting & 0,671 & 8,234 & $\geq 1,96$ (Signifikan) \\
Job Crafting $\rightarrow$ Work Engagement & 0,562 & 4,931 & $\geq 1,96$ (Signifikan) \\
\hline
\end{tabular}

Sumber: Output SmartPLS 3.0 (2020)

Tabel 3.

INDIRECT EFFECTS

\begin{tabular}{cccc}
\hline Path & Origin Sample & T- Statistics & Keterangan \\
\hline $\begin{array}{c}\text { Learning Goal Orientation } \rightarrow \text { Work } \\
\text { Engagement } \rightarrow \text { Job Crafting }\end{array}$ & 0,378 & 3,987 & $\geq 1,96$ \\
(Signifikan)
\end{tabular}

Sumber: Output SmartPLS 3.0 (2020)

Hal tersebut didukung oleh hasil wawancara salah satu karyawan, beliau memiliki sebuah keinginan untuk belajar hal baru dengan penuh semangat, namun tingginya antusias tersebut kurang didukung oleh perusahaan. Di mana saat beliau ingin menanyakan sesuatu permasalahan yang berkaitan dengan pekerjaannya, atasannya kurang memberikan solusi terhadap masalah tersebut. Hasil yang signifikan antara learning goal orientation dan work engagement dibuktikan dari adanya antusiasme yang tinggi dari karyawan dalam meningkatkan kemampuannya di mana hal tersebut mempu membangkitkan semangat kerja karyawan. Jones et al., (2015) menemukan efek bagi learning goal orientation dengan work engagement dapat mendukung hal tersebut, di mana seseorang dengan learning goal orientation yang tinggi berkesempatan untuk mempelajari kemampuan atau pengetahuan baru yang secara proaktif akan melibatkan tugas yang lebih kompleks yang bertujuan untuk menambah pengalaman kerja karyawan. Perilaku proaktif menunjukkan bahwa seseorang mempunyai inisiatif untuk melakukan suatu perubahan, yang mana perubahan tersebut menjadikan orang tersebut menjadi lebih baik. Diperkuat penelitian oleh Baum et al., (2011), individu dengan learning goal orientation yang kuat lebih rentan untuk terlibat aktif dalam bereksperimen, di mana kemungkinan mereka akan lebih banyak untuk mengeksplorasi dan mempelajari pengetahuan baru melalui pengalaman pribadi dalam kehidupan nyata dan mencoba menerapkannya ke dalam pekerjaannya.

\section{Pengaruh Learning Goal Orientation terhadap Job Crafting Karyawan PT. Boma Bisma Indra (Persero) Surabaya}

Bersumber pada temuan analisa learning goal orientation memiliki pengaruh bagi job crafting secara signifikan dan memiliki arah positif. Artinya jika bertambahnya learning goal orientation, job crafting pun juga semakin tinggi, itu dikarenakan makna positif yang memiliki arti berbanding lurus.

Nilai rata-rata variabel job crafting terbilang kategori sedang. Sehingga tenaga kerja PT. Boma Bisma Indra (Persero) Surabaya tidak semuanya menerapkan job crafting (seeking challenges) dalam bekerja. Hal ini diperkuat berdasarkan wawancara dengan beberapa karyawan. Dalam wawancara tersebut ada karyawan yang mengatakan bahwa beliau tidak menerapkan job crafting dalam pekerjaannya. Di mana beliau tidak setuju dengan adanya tugas atau pekerjaan tambahan tanpa adanya insentif atau reward dari perusahaan. Namun berbeda halnya dengan salah satu karyawan yang mengatakan bahwa beliau menerapkan job crafting dalam pekerjaannya, di mana beliau tertantang untuk mengemban tugas yang lebih besar yaitu dengan secara proaktif menawarkan dirinya sebagai ketua pelaksana dalam suatu proyek baru. Beliau juga menambahkan jika keinginan tersebut dapat terealisasikan, maka beliau dapat belajar banyak hal dan pengalaman baru ketika beliau menjadi seorang ketua proyek.

Tingginya learning goal orientation karyawan PT. Boma Bisma Indra (Persero) Surabaya meningkatkan job crafting mereka. Pernyataan tersebut didukung penelitian dari Nabi \& Ismail (2016) yang menyebutkan adanya pengaruh dengan arah positif antara learning goal orientation dan job crafting. Seseorang dengan pola pikir learning goal orientation memiliki dampak pada perilaku job 
crafting. Hasil penelitian tersebut sejalan dengan penelitian yang dilakukan oleh Lyons et al., (2006) yang menemukan adanya perilaku learning goal orientation pada karyawan sektor publik dalam melakukan mendesain pekerjaannya, di mana mereka secara proaktif melakukan pekerjaan yang menantang. Belschak \& Den Hartog (2010) menyebutkan bahwa karakteristik dari karyawan yang memiliki motivasi intrinsik dalam bekerja akan mencari tahu dan berkenan untuk mengambil tugas yang menantang.

\section{Pengaruh Job Crafting terhadap Work Engagement Karyawan PT. Boma Bisma Indra (Persero) Surabaya}

Hasil analisis statistik menjelaskan job crafting memiliki pengaruh yang bersifat signifikan dengan arah yang positif pada work engagement. Artinya, tinggi rendahnya job crafting akan berbanding lurus dengan work engagement.

Hasil deskriptif responden rata-rata untuk variabel job crafting termasuk sedang dan variabel work engagement tergolong dalam kategori sedang. Wawancara dengan salah satu karyawan pun memberi hasil bahwa beliau sudah tidak ada beban kerja, beliau tertarik untuk mengerjakan pekerjaan yang lain. Hal tersebut dilakukan karena beliau merasa ingin terus melakukan suatu pekerjaan dan beliau mengatakan bahwa beliau larut dalam pekerjaannya.

Dengan demikian, job crafting yang dimiliki oleh tenaga kerja PT. Boma Bisma Indra (Persero) Surabaya bisa meningkatkan work engagement mereka. Temuan ini selaras dengan penelitian dari Lu et al., (2014) menyebutkan bahwasanya job crafting berdampak positif bagi work engagement, hal tersebut didukung penelitian dari Petrou et al., (2012) yang menyebutkan bahwa karyawan yang setiap harinya mencari tantangan dalam menyelesaikan pekerjaannya akan semakin terikat dengan pekerjaan. Sehingga, job crafting akan memiliki dampak positif bagi work engagement karyawan.

\section{Pengaruh Learning Goal Orientation terhadap Work Engagement melalui Job Crafting PT. Boma Bisma Indra (Persero) Surabaya}

Dari hasil pengujian menyatakan bahwa hipotesis 4 diterima. Hal ini diartikan bahwa job crafting dapat memediasi learning goal orientation terhadap work engagement. Fungsi mediasi dari variabel job crafting terlihat karena adanya antusias karyawan dalam belajar, di mana karyawan lebih memilih pekerjaan yang menantang. Hal tersebut diketahui berdampak pada work engagement karyawan. Di mana pernyataan tersebut sesuai dengan definisi work engagement, yaitu karyawan akan mempunyai semangat/antusias dalam pekerjaannya. Hal ini dapat memberikan suatu informasi bahwa variabel job crafting (seeking challenges) menjadi variabel mediasi antara learning goal orientation terhadap work engagement. Hasil penelitian dari Matsuo (2018) menunjukkan bahwa individu dengan perilaku learning goal orientation yang tinggi tidak hanya termotivasi secara intrinsik dalam memperoleh pengetahuan dan keterampilan tetapi juga mendesain ulang pekerjaan mereka menjadi lebih menantang. Dengan begitu dapat diartikan bahwa job crafting (seeking challenges) dapat menjadi mediasi pengaruh antara learning goal orientation terhadap work engagement.

\section{KESIMPULAN}

Penelitan ini mendeskripsikan variabel learning goal orientation berpengaruh signifikan dan positif pada work engagement tenaga kerja PT. Boma Bisma Indra (Persero) Surabaya. Dari temuan itu menunjukkan tenaga kerja PT. Boma Bisma Indra (Persero) Surabaya menerapkan learning goal orientation pada pekerjaannya sehingga berdampak pada peningkatan work engagement karyawan. Learning goal orientation berpengaruh signifikan dan positif pada job crafting karyawan PT. Boma Bisma Indra (Persero) Surabaya. Learning goal orientation yang bertambah akan berdampak pada meningkatnya job crafting karyawan. Job crafting berpengaruh signifikan dan positif pada work engagement. Learning goal orientation menunjukkan pengaruh tidak langsung pada work engagement yang disesuaikan oleh job crafting. Jadi semakin tinggi learning goal orientation diterapkan oleh karyawan akan memunculkan job crafting karyawan dan berdampak pada meningkatnya work engagement dari karyawan. 
Terry Luana Ameliasari. Peran Job Crafting sebagai Mediasi Learning Goal Orientation dan Work Engagement

Implikasi manajerial pada penelitian ini yaitu perusahaan dapat mempertahankan adanya pengembangan kompetensi dan pelatihan bagi karyawan baik itu didalam maupun di luar perusahaan yang telah tercantum dalam Annual Report PT. Boma Bisma Indra (Persero), harapannya saran tersebut dapat mempertahankan perilaku learning goal orientation yang dimiliki karyawan. Perusahaan juga dapat melakukan analisis jabatan berdasarkan job description untuk dapat menilai kualitas karyawan sesuai dengan keahliannya. Hal tersebut akan membuat karyawan merasa nyaman karena sesuai dengan pekerjaan yang mereka lakukan sehingga mampu meningkatkan work engagement dari karyawan. Selain itu, perusahaan dapat memberikan insentif atau reward kepada karyawan yang sudah melakukan pekerjaan di luar pekerjaan utamanya. Dengan adanya insentif atau reward akan memicu karyawan untuk dapat meningkatkan kualitas kerjanya sehingga job crafting yang dimiliki karyawan dapat semakin diimplementasikan dalam perusahaan. Harapan untuk studi selanjutnya adalah dapat mengembangkan studi ini dengan menambahkan variabel lain dari dimensi goal orientation, yaitu prove (performance) goal orentation dan avoid (performance) goal orientation.

\section{DAFTAR PUSTAKA}

Adriaenssens, J., De Gucht, V., \& Maes, S. (2015). Association of goal orientation with work engagement and burnout in emergency nurses. Journal of Occupational Health, 57(2), 151-160.

Bakker, A. B., Rodríguez-Muñoz, A., \& Sanz Vergel, A. I. (2016). Modelling job crafting behaviours: Implications for work engagement. Human Relations, 69(1), 169-189. https://doi.org/10.1177/0018726715581690

Baum, J., Bird, B., \& Singh, S. (2011). Practical intelligence of entrepreneurs: Antecedents and a link with new venture growth. Personnel Psychology, 64(2), 397-425.

Belschak, F. D., \& Den Hartog, D. N. (2010). Pro-self, prosocial, and pro-organizational foci of proactive behaviour: Differential antecedents and consequences. Journal of Occupational and Organizational Psychology, 83(2), 475-498.

Bukit, B., Malusa, T., \& Rahmat, A. (2017). Pengembangan Sumber Daya Manusia: Teori, Dimensi Pengukuran, dan Implementasi dalam Organisasi.

Creed, P. A., Fallon, T., \& Hood, M. (2009). The relationship between career adaptability, person and situation variables, and career concerns in young adults. Journal of Vocational Behavior, 74, 219-229.

Deci, E. L., \& Ryan, R. M. (2008). Self-determination theory: a marcotheory of human motivation, development, and health. Canadian Psychology, 49(3), 182-185.

Demerouti, E. (2014). Design Your Own Job Through Job Crafting. European Psychologist, 237-247.

Demerouti, E., Bakker, A. B., \& Gevers, J. M. P. (2015). Job crafting and extra-role behavior: The role of work engagement and flourishing. Journal of Vocational Behavior, 91, 87-96. http://dx.doi.org/10.1016/j.jvb.2015.09.001

Dragoni, L., Tesluk, P. E., Russell, J. E. A., \& Oh, I.-S. (2009). Understanding Managerial Development: Integrating Developmental Assignments, Learning Orientation, and Access to Developmental Opportunities in Predicting Managerial Competencies. Academy of Management Journal, 52(4), 731-743. http://journals.aom.org/doi/10.5465/amj.2009.43669936

Dweck, C. S. (1986). Motivational processes affecting learning. Special Issue: Psychological science and education. American Psychologist, 41(10), 1040-1048.

Eppler, M. A., \& Harju, B. L. (1997). Achievement motivation goals in relation to academic 
performance in traditional and nontraditional college students. Research in Higher Education, $38(5), 557-573$.

Jones, J. L., Davis, W. D., \& Thomas, C. H. (2015). Is Competition Engaging? Examining the Interactive Effects of Goal Orientation and Competitive Work Environment on Engagement. Human Resource Management, 56(3), 389-405.

Joo, B. K., \& Park, S. (2010). Career Satisfaction, organizational commitment, and turnover intention: The effect of goal orientation, organizational learning culture and developmental feedback. Leadership \& Organization Development Journal, 31(6), 482-500.

Kahn, W. A. (1990). Psychological Conditions of Personal Engagement an Disengagement at Work. Academy of Management Journal, 33(4), 692-742.

Kirkendall, C. D. (2013). Job Crafting: The Pursuit of Happiness at Work. Wright State University.

Lu, C. qin, Wang, H. jiang, Lu, J. jing, Du, D. yang, \& Bakker, A. B. (2014). Does work engagement increase person-job fit? The role of job crafting and job insecurity. In Journal of Vocational Behavior (Vol. 84, Issue 2). Elsevier B.V.

Lyons, S. T., Duxbury, L. E., \& Higgins, C. A. (2006). A Comparison of the Values and Commitment of Private Sector, Public Sector, and Parapublic Sector Employees. Public Administration Review, 66(4), 279-291.

Maden, C. (2015). Linking high involvement human resource practices to employee proactivity. Personnel Review, 44(5), 720-738.

Marciano, P. L. (2010). Carrots and Stichs Don't Work Build a Culture of Employee Engagement with the Principles of Respect. Mc. Graw Hill.

Matsuo, M. (2018). Effect of learning goal orientation on work engagement through job crafting: A moderated mediation approach. Emerald Publishing Limites, 220-233.

Nabi, M. A. G., \& Ismail, W. K. W. (2016). Job Crafting In Public Sector. International Journal of Business Research and Management, 7(4), 63-81.

Petrou, P., Demerouti, E., Peeters, M. C. W., Schaufeli, W. B., \& Hetland, J. (2012). "Crafting a job on a daily basis: contextual correlates and the link to work engagement." Journal of Organizational Behavior, 33(8), 1120-1141.

Radstaak, M., \& Hennes, A. (2017). Leader - member exchange fosters work engagement: The mediating role of job crafting. Journal of Industrial Psychology, 40, 1-11.

Sasmita, B. (2018). Bab 1 Pendahuluan. https://docplayer.info/57211426-Bab-1-pendahuluan-1-1latar-belakang-masalah.html

Schaufeli, W. B., \& Bakker, A. B. (2004). Job demands, job resources, and their relationship with burnout and engagement : a multi-sample study. Journal of Organizational Behavior, 315(March 2003), 293-315.

Setyawati, S. M., \& Nugrohoseno, D. (2019). Praktik SDM, Job Crafting dan Work Engagement terhadap Kinerja Karyawan. Jurnal Ilmu Manajemen, 7(3), 619-628.

Slemp, G. S., \& Vella-Brodrick, D. A. (2014). Optimising employee mental health: the relationship between intrinsic need satisfaction, job crafting, and employee well-being. Journal of Happiness 
Terry Luana Ameliasari. Peran Job Crafting sebagai Mediasi Learning Goal Orientation dan Work Engagement

Studies, 15, 957-977.

Thomassen, J. (2016). The relationship between job crafting and work engagement: the mediating role of workload and colleague support and the moderating role of self-efficacy Master Thesis Name of first supervisor. Human Resource Studies Faculty, 2-48.

Tims, M., Bakker, A. B., \& Derks, D. (2015). Job crafting and job performance: A longitudinal study. Organizational Psychologist, 9114-9928.

Turpunjung, A. D. (2017). HUBUNGAN ANTARA PERCEIVED ORGANIZATIONAL SUPPORT DENGAN EMPLOYEE ENGAGEMENT PADA KARYAWAN PTP NUSANTARA VIII (PERSERO) DAYEUH MANGGUNG GARUT, JAWA BARAT. Universitas Mercu Buana Yogyakarta.

VandeWalle, D. (1997). Development and validation of a work domain goal orientation instrument. Educational and Psychological Measurement, 57(6), 995-1015.

Vansteenkiste, W., Lens, W., \& Deci, E. L. (2006). Intrinsic versus extrinsic goal contents in selfdetermination theory: another look at the quality of academic motivation. Educational Psychologist, 19-31.

Wrzesniewski, A., \& Dutton, J. E. (2001). Crafting a Job: Revisioning Employees as Active Crafters of Their Work. Academy of Management Review, 26(2), 179-201. https://doi.org/10.5465/amr.2001.4378011

Yao, T., \& Fu, M. (2019). The Effect of Developmental Feedback on Employee Job Crafting: The Mediating Role of Learning Goal Orientation. Open Journal of Social Sciences, 7, 111-126.

Yuswardi. (2019). Analisis Faktor-Faktor yang Mempengaruhi Keterikatan Karyawan pada Hotel Berbintang di Batam. Jurnal Ekonomi \& Ekonomi Syariah, 2(2), 194-205.

Zhou, J. (2003). When the presence of creative coworkers is related to creativity: Role of supervisor close monitoring, developmental feedback, and creative personality. Journal of Applied Psychology, 88, 413-422. 